\title{
'L'acropathie ulcéro-mutilante familiale' with involvement of the distal mixed nerves and long bones fractures
}

\author{
A. JUŠIĆ, Z. RADOŠEVIĆ, N. GRČEVIĆ, V. HLAVKA, \\ R. PETRIČEVIĆ-MIGIĆ, AND V. HARTL-PRPIĆ \\ From the Department of Neurology and Neuropathology, Department of Medicine \\ and Institute of Radiology, Medical School, University of Zagreb, Zagreb, Yugoslavia
}

SUMMARY Two siblings are described with mutilating lesions of the feet and hands, with sensory disturbances and muscle amyotrophy. The motor and afferent nerve conduction velocities were at the lower limit of normal. The nerve action potentials disappeared, first with percutaneous stimulation of the fingers and later with more proximal direct nerve stimulation. Early in the course of the illness indolent fracture of different long bones appeared in both cases. Histology revealed severe loss of nerve fibres, especially of the thin nonmyelinated ones. Excessive proliferation of Schwann sheaths and endoneurium exceeded the amount of the usual reparation for loss of nerve fibres and could be considered as a specific feature. Obliterative vasculopathy also belongs to the picture of changes in the nerves, skin, and bones.

In 1852 Nélaton gave what was probably the first published report of perforating ulcers of the feet. In his opinion the disorder was one arising primarily in the bones. Many cases have been reported since the turn of the century and described as due to lumbosacral syringomyelia or to status dysraphicus.

In 1942 Thévenard gave the descriptive term of 'acropathie ulcéro-mutilante familiale' to the syndrome and defined it as occurring near puberty, usually affecting only the lower limbs, with peripheral loss of pain and temperature sensation and occasionally of all forms of sensation, with diminished or absent deep tendon reflexes, and trophic ulcerations. There was no muscular atrophy in his description.

Jughenn, Krücke, and Wadulla (1949) called the disease 'familiar neurovascular dystrophy of limbs'. No syringomyelia was found, only some dysontogenetic disorders of the spinal cord (angiectasis). In the trophic lesions there were many blood vessels with intimal proliferation sometimes sufficient to cause obliteration. Segmental demyelination with proliferation of Schwann cells was found in peripheral nerves.
In 1951 Denny-Brown reported the necropsy of a woman suffering from hereditary perforating ulcers of the feet. He found no evidence of significant pathology in the spinal cord or in the anterior nerve roots. However, there were definite changes in the dorsal root ganglia and afferent nerve trunks.

Denny-Brown related the entity of hereditary sensory neuropathy as a disease of the dorsal root ganglia, to Charcot-Marie-Tooth peroneal muscular atrophy, the latter representing the motor form of the degenerative disease, while the former represents the sensory one, linked by those cases of peroneal muscular atrophy which also show severe sensory change and trophic disorders (England and Denny-Brown, 1952).

Campbell and Hoffman (1964) described two families in which sensory radicular neuropathy occurred with mutilating lesions of the feet. The histological changes consisted of degeneration in the peripheral nerves, posterior roots, posterior root ganglia, and in the dorsal columns of the cord. In one of these patients well marked muscular wasting was present in all four limbs.

Some interesting clinical and histopatho- 
logical contributions to this syndrome were also brought by Heller and Robb (1955), Vignon, Megard, and Marin (1956), and recently by Lassmann, Partsch, and Sluga (1970).

In two siblings reported here, outstanding features were recurring trophic ulcers of the feet and hands, and painless fractures of long bones introduced with swelling. Sensory abnormalities and muscular atrophy were also observed in both cases which belonged to a sibship of seven members.

\section{CASE 1}

P.L. (born 1949, male) had no difficulties until the age of 6 years when his feet became swollen. At the same time the boy began to suffer from shooting pains 'just like a knife going through', mainly in the legs. The pain lasted for two or three seconds, most frequently occurring in the thigh and shin and to a lesser extent in the arms. After some weeks? ulcerations developed: the order of appearance $\vec{F}$ during the years is shown in Fig. 1a. Ulcers were mainly located at the pressure points of the foot


(a)

(b)

FIG. 1. Case 1. (a) Order of appearance of feet ulcers. The ulcers marked ' 1 ' appeared first. (b) The order of appearance of fractures of long bones. 
many affecting the dorsum of the foot. They had indurated edges and liquid or purulent discharge. Ulcers sometimes extended down to the bone and pieces of bone were extruded. Intermittent healing and relapses through many months were characteristic.

Five years after the onset of the disease fractures of long bones began. They were introduced by indolent swelling. The fractures were also painless and observed only when the patient walked. The fragments were palpable under the skin. Some of them were radiologically verified, the others were cured at home with rest in bed. The sequence of appearance is illustrated in Fig. 1b. The ulcers on the fingers of the hands appeared 12 years after the onset of the illness.

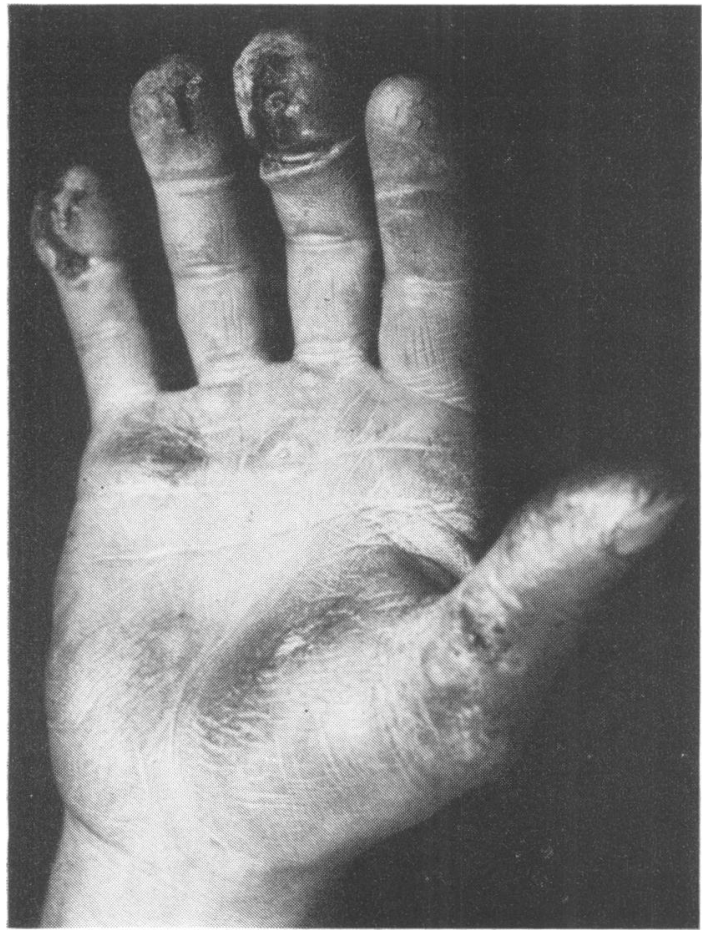

FIG. 2. Case 1. The trophic changes on the hand.

Abnormalities of micturition appeared a year before the affection of the hands. The patient had no awareness of bladder fullness and he had to void it by suprapubic manual pressure. Involuntary voiding appeared occasionally. Diarrhoea also occurred. Libido was significantly increased.
Some trophic changes improved with rest in bed for a month or so. Others led to spontaneous amputation of toes. All signs and symptoms were relapsing. The deformities grew bigger and were accompanied by inflammation and consecutive scars and elephantiasis, so that amputation of the legs was performed first below the knee on the right side, and afterwards above the knee on the left one.

NEUROLOGICAL EXAMINATION The patient was above average intelligence. There were no signs of deafness and no speech abnormalities. Both pupils were smaller than usual; the reaction of the pupils to light and to accommodation was sluggish. There was strong terminal nystagmus. No defect in the function of the remaining cranial nerves was noted.

The muscles were thin, hypotonic, and with reduced power, first in the distal muscles of the lower limbs and later in the small muscles of the hands. Atrophy was not obvious because of induration of the skin and subcutaneous tissue. There was unsteadiness and irregularity of movements in the heel-knee tests, but almost none in the finger-nose test.

The triceps surae reflex disappeared first. Soon afterwards the complete absence of knee, biceps, and brachioradialis jerks was noted. No plantar response was elicited on either side. The cremasteric and abdominal reflexes disappeared in order of ascendence. Sphincter deficiency occurred later in the course of the disease.

The senses of pain, temperature, and touch were highly reduced over both hands and the lower third of the forearms. They were almost lost below the knees, and impaired to some degree up to the umbilicus. The sense of vibration was almost normal in the upper limbs, and completely absent at the tibial malleoli, knees and pelvis. The sense of position was present in the fingers of both hands, and absent in the toes and ankles on both sides.

The skin of the hands was thick, hyperkeratotic, and dry with indolent ulcers (Fig. 2). The nails were brittle and jutted. The feet were severely deformed with anteroposterior shortening, the skin greatly thickened, dark, with many sharp-edged ulcerations with unhealthy pink granulations and purulent discharge. There was a cubitus valgus on the left side (fracture deformity).

Arteries of the dorsum pedis were not palpable, perhaps because of the skin thickness. There was no spina bifida and no glycosuria or albuminuria. Lumbar puncture revealed a cerebrospinal fluid with no abnormalities.

ELECTROMYOGRAPHIC FINDINGS In the small muscles of the foot there was neither spontaneous nor volun- 
tary activity. On stimulation of the appropriate nerves no direct muscle potential response was obtained. Some motor unit potentials of the anterior tibial muscle were prolonged and of greater than normal amplitude. With fibular nerve stimulation the direct muscle potential evoked in the anterior tibial muscle was greatly reduced in amplitude. Motor conduction velocity was slightly reduced $(37 \mathrm{~m} / \mathrm{sec})$.

The hand muscles showed some prolonged and high amplitude motor unit potentials with raised unloading frequency. No sensory nerve action potentials could be elicited at the wrist with ring stimulation of the second or fifth finger. The nerve action potentials with needle stimulation at the wrist could be elicited on previous examination over the elbow; with normal afferent conduction velocities. In controls they were always of smaller amplitude, disappearing finally. Motor conduction velocities of the ulnar and median nerves were at the lower limit of normal.

RADIOLOGY In 1961 the radiograph of the left foot already showed that the first metatarsal bone was thick-set with bluntly outlined transparencies in the distal part. Only the diaphysis was preserved of the third metatarsal bone. The fifth metatarsal bone had almost disappeared. In the basal phalanx of the second toe roundish transparencies were visible. Their number increased with time, especially in the os calcis.

Fractures of long bones were registered repeatedly. In 1963 there was a fracture of the distal metaphysis of the right femur. Dense shadows, irregular in shape, surrounding the fracture line were observed, most likely corresponding to calcifications in a haematoma. There were no signs of formation of endosteal callus. Rarefaction of the condyle was obvious. In the same year fractures of the tibia and fibula were observed. The fracture line went through the distal metaphysis; endosteal callus formation was poor. Perioseal callus formation and shadows due to calcifications in haematoma were demonstrated (Fig. 3) along the posterior part of the fracture line and laterally. Radiographs taken in 1966 revealed fracture of the distal metaphysis of the tibia
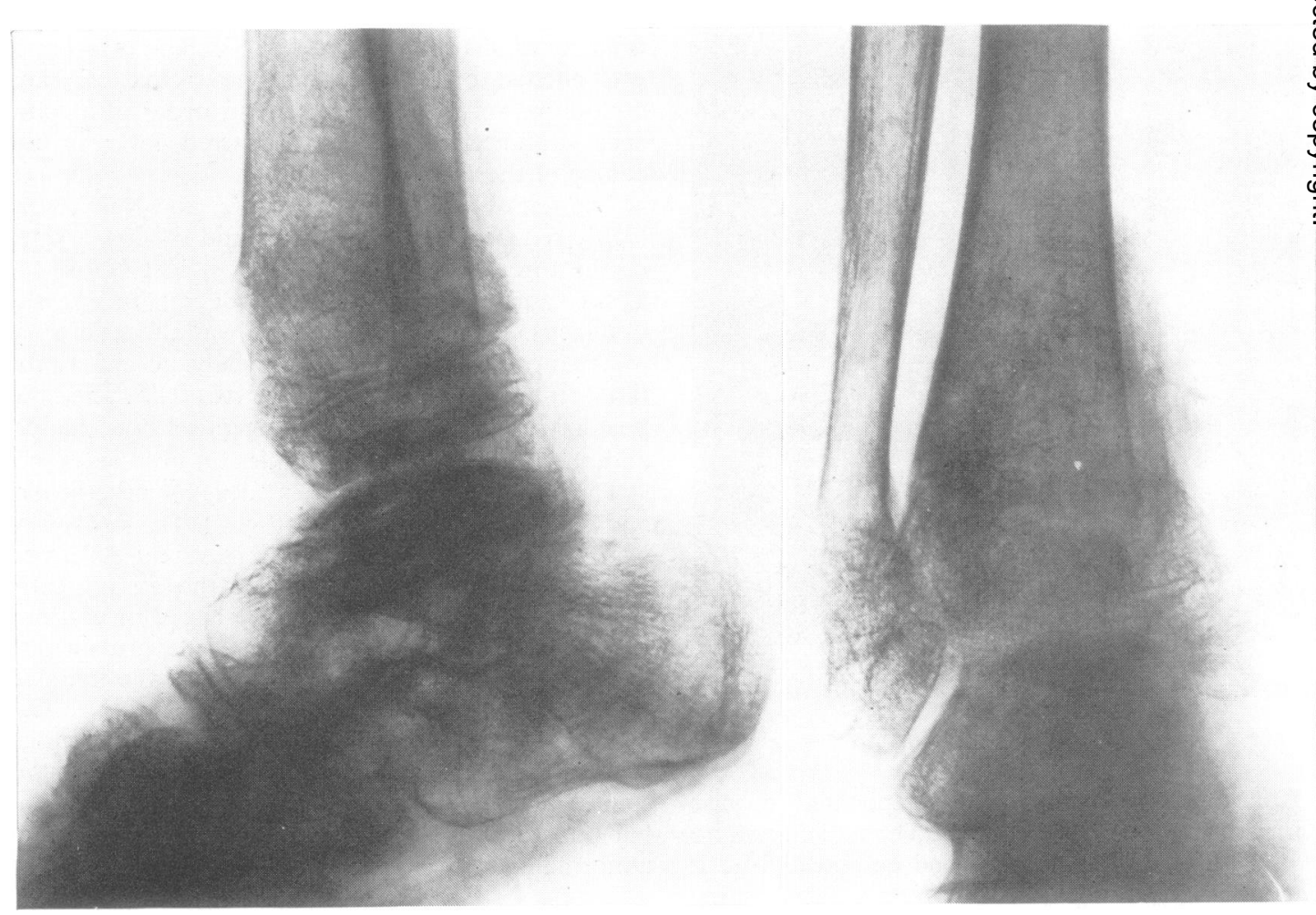

FIG. 3. Case 1. Fracture in the distal metaphysis of tibia and fibula. Roundish transparencies in tarsal bones. 
and fibula on the right side, with slight periosteal reaction. Condensation of bone structure was found in the metaphysis and epiphysis. At the same time the tarsal bones showed a high degree of rarefaction.

All fractures of long bones mentioned above showed no dislocation of fragment. The bone structure in the fracture region did not differ essentially from that of the rest of the bone. Periosteal callus formation was in general good; the endosteal callus formation was delayed.

HISTOLOGY The tibial and fibular nerves taken from the amputated leg were grossly atrophic, especially in the distal portions.

There was a severe loss of nerve fibres, most marked in the distal parts. The remaining fibres were of the large diameter type (Fig. 4a). In the cutaneous nerves the nerve fibres disappeared entirely. There were no signs of regeneration or of cellular phagocytosis. In the remaining fibres the myelin sheaths were almost normal. Abundant proliferation of the Schwann cells (Fig. 4b) and endoneurium did not follow entirely the pattern of loss of nerve fibres. Quite conspicuous proliferation was also seen in the relatively spared proximal portions of the nerves. In places, proliferation of Schwann sheaths and endoneurium produced typical 'onion-bulb' formations. The process obviously involved most severely the thin non-myelinated nerve fibres. The distal parts of nerve trunks con-

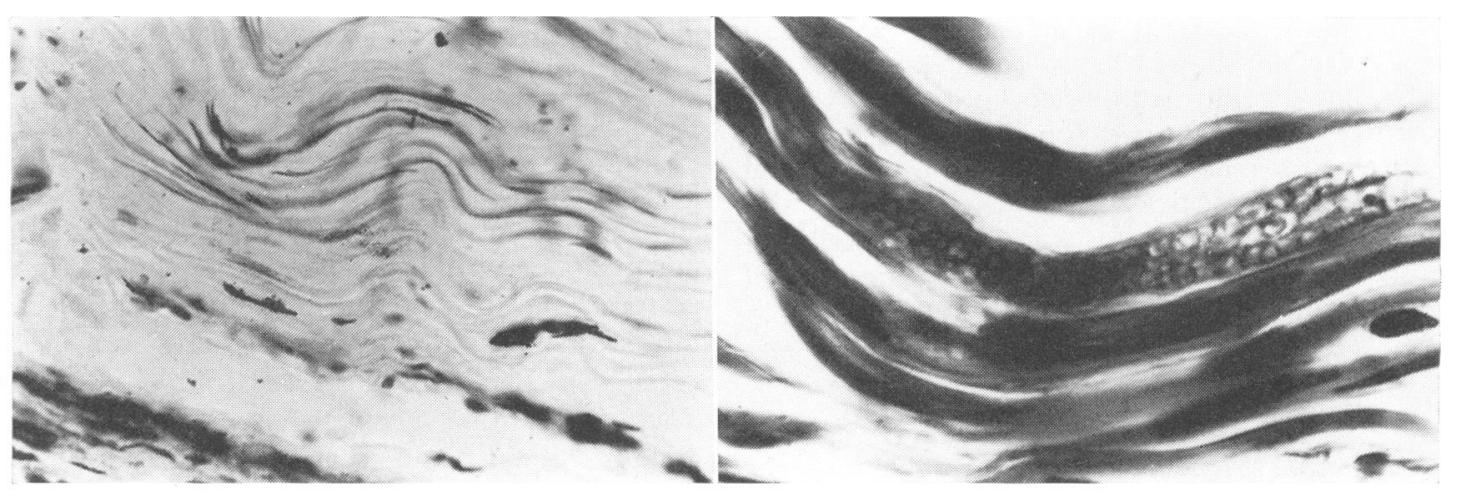

(a)

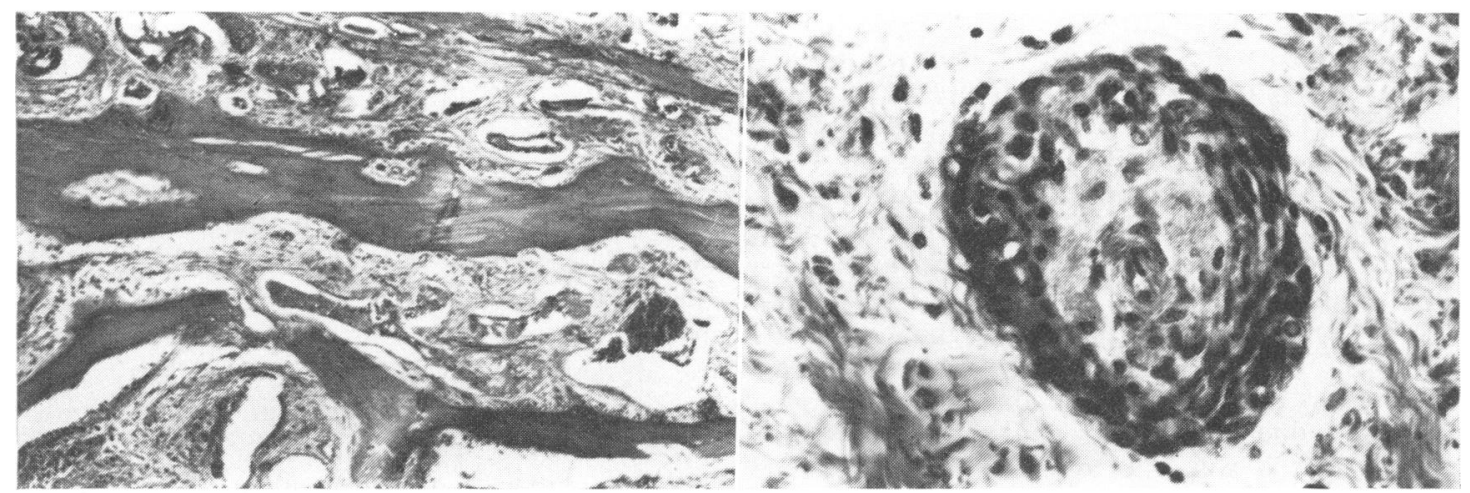

(c)

(d)

FIG. 4. Case 1. (a) Severe reduction of nerve fibres in the distal segment of the tibial nerve. Bielschowsky, $\times 250$. (b) Proliferation of Schwann cells and endoneurium. Luxol Fast Blue, $\times 900$. (c) Bone atrophy with trabecular disintegration and medullary fibrosis. $H$ and $E, \times 100$. (d) Obliterative arteritis in the subcutaneous tissue. 
sisted almost entirely of proliferated Schwann cells and endoneurial tissue. In some places the appearance of the nerves resembled the neurofibromata of von Recklinghausen. There was some proliferation of perineurium and less of the epineurium. No deposition of any material like amyloid or mucus could be seen.

The blood vessels of the skin, nerves, and bones showed very conspicuous findings. The blood vessels showed proliferation of all layers, most marked subintimally. In some places it resembled recanalized thrombus, although no evidence of thrombotic material could be found. The changes increased towards the foot. The arterial and venous involvement was of the same degree in the distal parts (Fig. 4d).

In the skin, there was a severe obliterative vasculopathy and complete loss of the cutaneous nerves with general proliferation of the corium.

Osseous tissue from metatarsal and phalangeal bones (Fig. 4c) showed severe demineralization and trabecular atrophy with osteoclastic activity. Obliterative vasculopathy was found here too. The bone marrow was mostly fibrous and only occasional nests of haemopoietic cells were found.

A small muscle of the foot showed groups of atrophic fibres with proliferated sarcolemmal nuclei suggesting a neuronal type of atrophy.

\section{CASE 2}

P.M. (born 1937, female) had no trouble until the age of 10 years. At this time her right knee became swollen. It was entirely painless. A year later a painless fracture of the femur developed. The fracture line extended from the medial epycondyle into the knee joint. It was treated by immobilization and knee ankylosis with resection by Charnley's operation. Lightning pains were rather frequent. Six years after the first painless swellings, trophic ulcers appeared in the knee and later on the shin. They were also painless, disappeared in a month, and reappeared again. Ulcers of the same kind, with pieces of bone extruded, developed on the feet and afterwards on the fingers with mutilations. The mutilations of the feet resulted in an 'elephant's foot' deformity. The muscles were hypotrophic and hypotonic. It was not clear how far the deficit of movement was due to trophic and sensory changes and how far it was due to direct neuromuscular involvement. There were no ankle and knee jerks. Sensory involvement of high degree was found on feet and hands. The position sense was affected to only a minor degree.

This patient died at home at the age of 26 years because of some undefined abdominal distress.

\section{DISCUSSION}

According to Jughenn, Krücke, and Wadulla (1949) the changes of the blood vessels are the direct cause of the 'trophic changes', although the ultimate cause may be a lesion of the vegetative nervous system.

Denny-Brown (1951) located the primary process in the dorsal root ganglia and considered that the mutilating ulcerative changes resulted from the loss of pain sense and not as a result of the absence of 'any specific trophic nerves'. The loss of nerve fibres was considered due to secondary Wallerian degeneration. He also considered that the Schwann cell proliferation and amyloid deposition in the dorsal root ganglia were secondary. He did not find any significant changes in the blood vessels and found no evidence of muscular atrophy.

Van Bogaert (1953) described changes similar to those of Jughenn, Krücke, and Wadulla in the vessels and nerves. In his opinion it was not possible to decide whether the disease begins at the periphery or in the dorsal root ganglia. He sug- $\frac{?}{8}$ gested that within the group of "familial ulcers,, mutilating lesions of the extremities and acro osteolysis' there are various forms of the sameo disease with the substrate either in the spina ganglia, spinal nerve roots, or in the periphery The vascular changes were probably secondary.

In our material the pathological changes are significantly more developed in the distal parts of the limbs. The degenerative changes seem to involve particularly the thin nonmyelinated fibres, a finding which is more visible where large numbers of thick myelinated fibres are spared. It is known that most of the nerve fibres conducting pain and temperature sensation are nonmyelinated, belonging to the thinnest fibres of the peripheral nervous system. There are vasomotor, pilomotor, and secretomotor nonmyelinated fibres in sensory nerves and also in the dorsal roots. The terminal sensory nerve branches consist mostly of thin nonmyelinated fibres.

We consider that the primary disturbance is in the periphery and not in the dorsal root ganglia.

The excessive proliferation of Schwann cells and endoneurium leading to the onion-bulb formation, in our case exceeded the amount of 
the usual reparation of the loss of the nerve fibres and should be considered as a specific feature due to an unknown mechanism. This proliferation coincides with segmental degeneration but seems to appear before the degeneration becomes visible. In the nonmyelinated fibres under the thick proliferated sheath the axon was sometimes found practically undamaged. This picture is reminiscent of neurofibromata of von Recklinghausen.

The vasculopathy should also be of importance. In view of its distribution we have to postulate a dependence between the degenerative and proliferative lesions of the nerves and the vasculopathy. It seems reasonable to assume that the autonomic nervous system is primarily involved.

The almost normal afferent and efferent nerve conduction velocities accompanied by significant amplitude reduction of the direct muscle response also suggest loss of slower conducting fibres.

The fractures of long bones appearing again and again are peculiar to these siblings. We have not found similar observations in the literature. A single long bone fracture was described in a related case by Barraquer-Ferré and BarraquerBordas (1953), but that was most probably traumatic in origin.

\section{REFERENCES}

Barraquer-Ferré, L., and Barraquer-Bordas, L. (1953). De la sémiologie ganglio-radiculaire postérieure dans l'amyotrophie de Charcot-Marie-Tooth: troubles trophiques, douleurs fulgurantes, troubles sensitifs. Acta Neurologica et Psychiatrica Belgica, 53, 55-70.

Bogaert, L. van (1953). Essai de classement et d'interprétation de quelques acro-ostéolyses mutilantes et non mutilantes actuellement connues. Acta Neurologica et Psychiatrica Belgica, 53, 90-115.

Campbell, A. M. G., and Hoffman, H. L. (1964). Sensory radicular neuropathy associated with muscle wasting in two cases. Brain, 87, 67-74.

Denny-Brown, D. (1951). Hereditary sensory radicular neuropathy. Journal of Neurology, Neurosurgery, and Psychiatry, 14, 237-252.

England, A. C., and Denny-Brown, D. (1952). Severe sensory changes, and trophic disorder, in peroneal muscular atrophy (Charcot-Marie-Tooth type). Archives of Neurology and Psychiatry, 67, 1-22.

Heller, I. H., and Robb, P. (1955). Hereditary sensory neuropathy. Neurology (Minneap.), 5, 15-29.

Jughenn, H., Krücke, W., and Wadulla, H. (1949). Zur Frage der familiären Syringomyelie. (Klinisch-anatomische Untersuchungen über 'familiäre neuro-vasculäre Dystrophie der Extremitäten'.) Archiv für Psychiatrie und Nervenkrankheiten, 182, 153-176.

Lassmann, G., Partsch, H., and Sluga, E. (1970). Hereditäre sensorische Neuropathie. Proceedings of the 6th International Congress of Neuropathology, Paris, 1970, pp. 715716. Masson: Paris.

Nélaton (1852). Affection singulière des os du pied. Gazette des Hôpitaux Civils et Militaires, 25, 13-20.

Thévenard, A. (1942). L'acropathie ulcéro-mutilante familiale Revue Neurologique, 74, 193-212.

Vignon, G., Mégard, M., and Marin, A. (1956). Une observation anatomo-clinique d'acropathie ulcéro-mutilante. Presse Médicale, 64, 1954-1956. 